\title{
Cold hardiness of Pyrrhocoris apterus (Heteroptera: Pyrrhocoridae) from central and southern Europe
}

\author{
PLAMEN KALUSHKOV ${ }^{1}$ and OLDŘICH NEDVĚD ${ }^{2,3 *}$ \\ ${ }^{1}$ Institute of Zoology, Bulgarian Academy of Sciences, blvd. Tzar Osvododitel, 1000 Sofia, Bulgaria \\ ${ }^{2}$ Institute of Entomology, Academy of Sciences and ${ }^{3}$ Faculty of Biological Sciences, University of South Bohemia, Branišovská 31 , \\ 37005 České Budějovice, Czech Republic
}

Key words. Heteroptera, Pyrrhocoris apterus, survival, mortality, supercooling, low temperature, diapause, overwintering, oviposition, Bulgaria, Bohemia

\begin{abstract}
The cold hardiness of individuals from overwintering populations of a freeze susceptible bug Pyrrhocoris apterus from central and southern Europe differed significantly. Supercooling point (SCP) correlated well with both lethal temperature $\left(\mathrm{LT}_{50}\right)$ and lethal time $\left(\mathrm{Lt}_{50}\right)$, and is a good index of cold hardiness of adults during and after diapause. In January, diapause terminated, but cold hardiness was similar to that recorded in November; cold hardiness decreased slightly in March and markedly in May. Short exposure (less than a week) to higher temperatures before termination of diapause did not reduce the cold hardiness. Cold hardiness did not closely follow air temperatures. The Bulgarian bugs retained lower cold hardiness regardless of acclimation to harsh field conditions in the Czech Republic. The interpopulation difference is therefore a heritable character representing an adjustment to local climates.
\end{abstract}

\section{INTRODUCTION}

It has been demonstrated that cold hardiness differs between geographically separated populations of a single species. For example, the cold hardiness of the freeze tolerant Eurosta solidaginis (Diptera: Tephritidae) is related to the latitude of origin (Lee et al., 1995).

A comprehensive study of interpopulation differences in cold hardiness was published by Turnock et al. (1985, 1990, 1998). They compared the supercooling points (SCPs) of the pupae from six temperate populations of the freeze susceptible Delia radicum (Diptera: Anthomyidae). The mean values range from $-20^{\circ} \mathrm{C}$ to $-25.2^{\circ} \mathrm{C}$, and are not related to mean January temperatures that range from $+4.6^{\circ} \mathrm{C}$ to $-17.7^{\circ} \mathrm{C}$. The values of the upper limit of cold injury zone (ULCIZ) also did not differ between populations (all near $-12.5^{\circ} \mathrm{C}$ ). However, there was a clear difference in the lethal time at intermediate temperatures, i.e., between SCP and ULCIZ, when populations from England and British Columbia (temperate oceanic climate) and from Quebec and Manitoba (temperate continental climate) were compared.

Similarly, Pullin \& Bale (1989) found that the SCP of overwintering Aglais urticae (Lepidoptera: Nymphalidae) is similar $\left(-21^{\circ} \mathrm{C}\right)$ in both southern England and St. Petersburg, not withstanding the difference in winter severity.

Although there are several cryobiological studies (Hanč, 1998; Hanč \& Nedvěd, 1999; Hodková \& Hodek, 1994, 1997) on Pyrrhocoris apterus, all have been on a Bohemian population (central Europe). A comprehensive study of this species' cold hardiness in relation to its life cycle and ambient temperature has been published by Košt'ál \& Šimek (2000).
We compared several parameters of cold hardiness in the bug Pyrrhocoris apterus from two populations, one from central, the other from southern Europe. The measurements of cold hardiness were made four times during the course of a winter, which is rare in this type of study. The level of cold hardiness was related to the ambient temperatures at the places of origin and to the intensity of diapause.

\section{MATERIAL AND METHODS}

\section{Experimental animals}

Adult bugs were collected from two localities: near Sofia, Bulgaria $\left(42^{\circ} 45^{\prime} \mathrm{N}, 600 \mathrm{~m}\right.$ a.s.1.), and near Ceské Budějovice, Czech Republic (Bohemia; $49^{\circ} \mathrm{N}, 380 \mathrm{~m}$ a.s.1.), on four occassions: November 15th, 1997, January 18th, March 18th and May 18th, 1998. The samples were transferred to the institute in České Budějovice and kept outdoors for a few days in a box with linden seeds and filter paper, and water in vials. Monthly mean air temperatures were obtained from meteorological stations at the two localities. The body lengths and breadths, and fresh weights of 30 males and females from each locality were measured.

\section{Supercooling point}

Temperature of spontaneous crystallization (SCP) of body fluids of 32 individuals from each sample from each locality was measured in a device described by Nedvěd et al. (1995); the cooling rate was $10 \mathrm{~K} / \mathrm{h}$.

\section{Cold treatments}

To evaluate survival at low temperature, groups of 30 animals were put into Petri dishes with a piece of filter paper, and placed in temperature-controlled chambers at $-5,-7,-10,-12$, and $-15^{\circ} \mathrm{C}, \pm 0.5^{\circ} \mathrm{C}$. After different periods of time (from $6 \mathrm{~h}$ to 180 days), the dishes were removed, the animals were supplied with water, and allowed to recover in the laboratory at $25^{\circ} \mathrm{C}$ for $24 \mathrm{~h}$.

\footnotetext{
* Corresponding author; e-mail: nedved@entu.cas.cz.
} 
The estimated survival was based on the number of animals able to walk.

\section{Acclimation}

The change in cold hardiness during acclimation at low and high temperatures was studied in the November and January samples from the Bulgarian population. Groups of animals supplied with food and water were placed: (a) outdoors in the Czech Republic, in the same conditions as the Czech population, (b) in a laboratory at $25^{\circ} \mathrm{C}$ and short day (SD: 12L : 12D) conditions, (c) in a laboratory under long day (LD 18L : 6D) conditions. The precise durations of exposure are indicated in the tables of results. The SCPs were measured on samples of $30-40$ individuals of each sex from each location.

\section{Oviposition}

The intensity of diapause was measured as the duration of the pre-oviposition period. The experiments started on 26th-28th of November, January and March. Pairs of animals (30 per treatment) were put separately into Petri dishes with linden seeds, filter paper and a vial of water. They were kept at $25^{\circ} \mathrm{C}$, $18 \mathrm{~L}: 6 \mathrm{D}$, and observed daily. The period to the first egg batch was recorded for each female.

\section{Survival}

The proportion of survivors decreased with decreasing temperature or increased time of exposure, resulting in a sigmoidal shaped survival curves. The form of the relationship between survival and time or temperature of exposure was determined using a logistic regression (Statistica software, see Statsoft, 1997):

$$
S(t)=\frac{e^{a-b \cdot t}}{1+e^{a-b \cdot t}}
$$

The time of exposure that results in $50 \%$ survival $\left(\mathrm{Lt}_{50}\right)$ or the $\mathrm{LT}_{50}$ temperature are equal to $\mathrm{a} / \mathrm{b}$. The data enabled $\mathrm{Lt}_{50}$ and $\mathrm{LT}_{50}$ to be calculated but failed to fit the model (Nedvěd, 1998) where exposure time and temperature are combined in a multiplicative manner, resulting in two parameters: upper limit of the cold injury zone (ULCIZ), and sum of injurious temperatures (SIT). However, following the method of Casagrande \& Haynes (1976) the logarithm of $\mathrm{Lt}_{50}$ was plotted against the squared difference of exposure temperature and the theoretical upper threshold (Th) of $\mathrm{LT}_{50}$ to give a linear relationship:

$$
L t_{50}=E_{50} \cdot e^{-d \cdot(T h-T)^{2}}
$$

in which $\mathrm{E}_{50}$ is the level of exposure that kills $50 \%$ of the individuals in a given sample.

A multi-way ANOVA was used to reveal differences between sexes, populations, and months. When significant, five types of post-hoc tests were performed to show which treatments differ. No Bonferroni adjustments were used in these tests.

\section{RESULTS}

\section{Supercooling point}

The distribution of supercooling points within treatments was unimodal and slightly negatively skewed. As the two sexes did not differ ( $p$ value of this factor in ANOVA was greater than 0.1 ), the data were pooled. The two-way ANOVA showed highly significant differences between localities and months $\left(\mathrm{p}<10^{-6}\right)$, and for interactions between them $(\mathrm{p}=0.002)$. Animals from the two locations differed strongly in their ability to supercool, especially in November and January. The values of SCP in these two months were low and almost identical at each

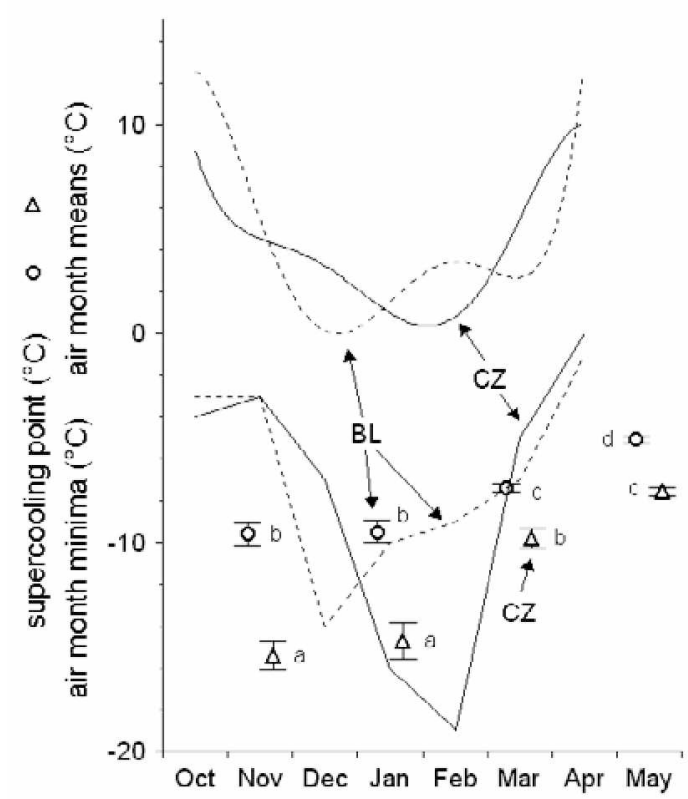

Fig. 1. Supercooling points of overwintering adults of the bug Pyrrhocoris apterus (mean $\pm \mathrm{SEM}$ ); and air temperature. Month minima - broken lines; monthly means - curves (polynomial fit). Bulgarian population - circles; Bulgarian air temperatures - dotted; Bohemian population - triangles; Bohemian air temperatures - solid lines. Letters indicate similarity in mean SCP determined by post-hoc tests (LSD, Duncan's, and Newman-Keuls, $\alpha=5 \%$ ).

location, and then increased to intermediate values in March and high values in May (Fig. 1).

\section{Lethal time}

The estimated period of exposure at constant subzero temperatures required to kill $50 \%$ of a sample (lethal time $-\mathrm{Lt}_{50}$ ) decreased with decreasing temperature, and followed a pattern similar to the differences in SCP (Table 1). There was a significant correlation between $\mathrm{SCP}$ and $\mathrm{Lt}_{50}$ (for exposure at $-7^{\circ} \mathrm{C}: \mathrm{p}=0.004$ ). The $\mathrm{Lt}_{50} \mathrm{~S}$ of bugs collected in winter were longer than those of bugs collected in March, which were longer than those of bugs collected in May. The Czech bugs always had longer $\mathrm{Lt}_{50} \mathrm{~S}$ than Bulgarian bugs. Due to the character of this parameter, computing the standard errors and comparative statistical tests were not possible.

TABLE 1. Lethal times ( $\left(\mathrm{t}_{50}\right.$, in days) of overwintering adults of the bug Pyrrhocoris apterus from Bulgaria (BL) and Czech Republic (CZ) kept at constant subzero temperatures.

\begin{tabular}{ccccccc}
\hline Locality & Month & $-15^{\circ} \mathrm{C}$ & $-12^{\circ} \mathrm{C}$ & $-10^{\circ} \mathrm{C}$ & $-7^{\circ} \mathrm{C}$ & $-5^{\circ} \mathrm{C}$ \\
\hline BL & Nov & - & 0.5 & 6.5 & 31 & 40 \\
BL & Jan & - & 0.9 & 5.5 & 20 & 30 \\
BL & Mar & - & - & 0 & 4.5 & 25 \\
BL & May & - & - & - & 0 & $<1$ \\
CZ & Nov & 3.3 & - & 35 & 117 & - \\
CZ & Jan & 0.33 & - & 36 & 51 & - \\
CZ & Mar & - & - & $<1$ & 12 & 41 \\
CZ & May & - & - & - & 1.5 & 3.8 \\
\hline
\end{tabular}

Zero value indicates that no individual survived for $1 \mathrm{~h}$, value $<1$ that less than $50 \%$ of sample survived for one day. 
TABLE 2. Lethal temperatures $\left(\mathrm{LT}_{50},{ }^{\circ} \mathrm{C}\right)$ of overwintering adults of the bug Pyrrhocoris apterus from Bulgaria (BL) and Czech Republic (CZ) kept for 1 to 10 days at constant subzero temperatures. Theoretical upper threshold of $\mathrm{LT}_{50}\left(\mathrm{Th},{ }^{\circ} \mathrm{C}\right)$, and exposure level associated with $50 \%$ survival $\left[\mathrm{E}_{50}\right.$, day $\left.\exp \left(\mathrm{K}^{2}\right)\right]$ calculated using Cassagrande and Haynes' (1976) method.

\begin{tabular}{ccrccccc}
\hline Locality & Month & 1 day & 3 days & 5 days & 10 days & Th & $\mathrm{E}_{50}$ \\
\hline BL & Nov & -10.0 & -9.6 & -9.1 & -8.7 & & \\
BL & Jan & -9.8 & -8.6 & -8.9 & -8.4 & & \\
BL & Mar & -7.9 & -7.0 & -6.7 & -5.8 & -4.9 & 12.7 \\
BL & May & $>-5$ & 0 & 0 & - & & \\
CZ & Nov & -15.4 & -15.0 & -13.5 & -11.2 & -10.2 & 10.7 \\
CZ & Jan & -14.4 & -13.4 & -12.6 & -11.0 & -10.1 & 11.1 \\
CZ & Mar & -8.4 & - & -8.2 & -6.9 & & \\
CZ & May & -7.1 & -5.2 & $>-5$ & - & & \\
\hline
\end{tabular}

Zero value indicates that no individual survived exposure to $-5^{\circ} \mathrm{C}$ for these particular times, value $>-5$ that less than $50 \%$ of sample survived exposures of the particular duration.

\section{Lethal temperature}

The estimated temperatures at which $50 \%$ of a sample died (lethal temperature - $\mathrm{LT}_{50}$ ) in a defined period of exposure increased with increasing exposure, but only by a few degrees or fractions of a degree. The $\mathrm{LT}_{50}$ values followed a pattern similar to the differences in SCP and $\mathbf{L t}_{50}$ (Table 2). Winter samples had a low $\mathrm{LT}_{50}$, the March samples of identical exposure durations had much higher values, and the $\mathrm{LT}_{50}$ in May was even higher. The Czech bugs always had a lower $\mathrm{LT}_{50}$ than the Bulgarian bugs. Due to the nature of this parameter, computing standard errors and comparative statistical tests were not possible. Values of $\mathrm{LT}_{50}$, after one or three days exposure, were close to the mean SCP in most treatments, whereas the $\mathrm{LT}_{50}$ after ten or even five days exposure seemed to be higher. There was a strong correlation between SCP and $\mathrm{LT}_{50}$ (after five days exposure: $\mathrm{p}=0.0002$ ). The increase in $\mathrm{LT}_{50}$ with duration of exposure in some treatments followed the exponential squared pattern, which gave the theoretical upper threshold $\mathrm{LT}_{50}$ and associated exposure level cited in Table 2. When compared with the $\mathbf{L t}_{50}$ values (Table 1), the upper threshold of $\mathrm{LT}_{50}$ appears to correspond to an exposure of about one month.

\section{Oviposition}

Animals from the two locations differed in their preoviposition periods, which were used as an indication of diapause intensity, in November and March, but not in

TABLe 3. Preoviposition period (days) of overwintering adults of the bug Pyrrhocoris apterus from Bulgaria (BL) and Czech Republic (CZ).

\begin{tabular}{ccrcc}
\hline Locality & Month & $\begin{array}{r}\text { POP (days) } \\
\text { mean } \pm \text { S.D. }\end{array}$ & T S & L D N-K \\
\hline BL & Nov & $12.1 \pm 3.2$ & $\mathrm{~d}$ & $\mathrm{c}$ \\
BL & Jan & $7.7 \pm 1.8$ & $\mathrm{c}$ & $\mathrm{b}$ \\
BL & Mar & $1.7 \pm 0.9$ & $\mathrm{a}$ & $\mathrm{a}$ \\
$\mathrm{CZ}$ & Nov & $15.5 \pm 4.4$ & $\mathrm{e}$ & $\mathrm{d}$ \\
$\mathrm{CZ}$ & Jan & $8.8 \pm 2.7$ & $\mathrm{c}$ & $\mathrm{b}$ \\
$\mathrm{CZ}$ & Mar & $3.4 \pm 1.0$ & $\mathrm{~b}$ & $\mathrm{a}$ \\
\hline
\end{tabular}

Letters indicate similarity: T S - Tukey and Scheffé tests, L D N-K - LSD, Duncan's, and Newman- Keuls tests.
TABLE 4. Changes in the supercooling point $\left({ }^{\circ} \mathrm{C}\right)$ after exposure of overwintering adults of the bug Pyrrhocoris apterus from Bulgaria to outdoor and laboratory conditions in the Czech Republic.

\begin{tabular}{crrcc}
\hline \multirow{2}{*}{ Month } & \multirow{2}{*}{$\begin{array}{c}\text { Duration } \\
\text { (weeks) }\end{array}$} & \multicolumn{3}{c}{ Mean \pm S.D. $\left({ }^{\circ} \mathrm{C}\right)$} \\
\cline { 3 - 5 } & & & \multicolumn{2}{c}{ Ouboratory $\left(25^{\circ} \mathrm{C}\right)$} \\
\cline { 3 - 5 } & & $-9.6 \pm 3.8$ & - & - \\
\hline Nov & & & SD 12L : 12D LD 18L : 6D \\
Nov & 1 & $-10.2 \pm 3.6$ & $-9.7 \pm 3.6$ & $-9.2 \pm 3.4$ \\
Nov & 4 & $-9.7 \pm 3.7$ & $-8.0 \pm 2.4$ & $-7.6 \pm 1.5$ \\
Nov & 10 & $-10.2 \pm 3.1$ & - & - \\
Jan & 0 & $-9.5 \pm 3.0$ & - & - \\
Jan & 1 & - & $-7.9 \pm 2.2$ & $-7.1 \pm 1.4$ \\
Jan & 4 & - & $-7.0 \pm 1.4$ & $-6.0 \pm 0.4$ \\
\hline
\end{tabular}

January. The individuals collected in the Czech Republic had a constantly longer period than those collected in Bulgaria. The period gradually shortened as the season progressed. In May, the animals in the field had already started to oviposit.

Two-way ANOVA showed highly significant differences between localities and months $\left(p<10^{-6}\right)$, and only a slight interaction between the two factors $(p=0.04)$. The correlation between mean preoviposition period and SCP was weak ( $p=0.12$ ), as was that with $\mathrm{LT}_{50}$ (five days exposure, $\mathrm{p}=0.06$ ), and stronger with $\mathrm{Lt}_{50}$ (measurements at $-7^{\circ} \mathrm{C}, \mathrm{p}=0.03$ ).

\section{Acclimation}

During acclimation of the Bulgarian population to outdoor conditions in the Czech Republic, and laboratory conditions $\left(25^{\circ} \mathrm{C}, \mathrm{LD}\right.$ or SD), the SCP differed between conditions (outdoor, laboratory at two photoperiods) and changed with time (two-way ANOVA showed significant differences between conditions and time, with no interaction between these two factors), in the experiments started in November and January.

The SCPs remained unchanged (Table 4) even after 10 weeks of acclimation to outdoor contitions. In the November sample, the SCPs were higher for bugs kept in laboratory than outdoors ( $p=0.015)$, independent of photoperiod. The increase was much greater after 4 weeks than 1 week of acclimation $(p=0.004)$. In the January sample, the increase in SCPs occurred after one week of acclimation. High temperature acclimation under long day conditions was more effective than under short days $(\mathrm{p}=0.0014)$.

\section{Size}

Diferences in fresh weight and body size (Table 5) were highly significant (always $\mathrm{p}<10^{-4}$ ) both between

TABLE 5. Size (means \pm S.D.) in November of overwintering adults of the bug Pyrrhocoris apterus from Bulgaria (BL) and Czech Republic (CZ).

\begin{tabular}{cccrc}
\hline Locality & Sex & $\begin{array}{c}\text { Fresh weight Body length } \\
\text { (mg) }\end{array}$ & $\begin{array}{c}\text { Pronotum } \\
\text { (mm) }\end{array}$ & breadth (mm) \\
\hline BL & male & $30 \pm 6$ & $8.3 \pm 0.5$ & $2.7 \pm 0.2$ \\
BL & female & $35 \pm 8$ & $9.1 \pm 0.5$ & $2.9 \pm 0.2$ \\
CZ & male & $36 \pm 5$ & $9.5 \pm 0.4$ & $3.1 \pm 0.2$ \\
CZ & female & $41 \pm 7$ & $10.0 \pm 0.5$ & $3.2 \pm 0.2$ \\
\hline
\end{tabular}


sexes (males smaller) and populations (Bulgarian smaller).

\section{DISCUSSION}

\section{Supercooling and survival}

There was a strong correlation between SCP, and both lethal temperature $\left(\mathrm{LT}_{50}\right)$ and lethal time $\left(\mathrm{Lt}_{50}\right)$. Pyrrhocoris apterus is freeze susceptible (chill tolerant according to Bale, 1993, 1996), but the SCP of a substantial number of individuals was several degrees lower than the mean value, and they survived for a few days at temperatures close to the mean SCP. $\mathrm{LT}_{50}$ after one or three days exposure were close to the mean SCP, the $\mathrm{LT}_{50}$ after five or ten days were higher but still strongly correlated to SCP. Thus we confirmed previous statements by Hodková \& Hodek (1994) and by Košt'ál \& Šimek (2000) that SCP provides a good index of cold hardiness in P. apterus.

The increase in $\mathrm{LT}_{50}$ with duration of exposure in some treatments followed the exponential squared pattern found earlier in a chrysomelid beetle Oulema melanopus (Casagrande \& Haynes, 1986), not the day-degree pattern found in the collembolan Orchesella cincta (Nedvěd, 1998; Nedvěd et al., 1998). On the other hand, survival of larvae of $P$. apterus followed the day-degree pattern (Hanč, 1998; Hanč \& Nedvěd, 1999).

Due to high variability, a substantial number of individuals in some samples had SCP values much lower than the mean value. They did not freeze at the constant temperature close to the mean SCP, and survived a few days at this temperature. That is why the $\mathrm{Lt}_{50} \mathrm{~S}$ at temperatures close to the mean SCP extended to several days.

\section{Cold hardiness and diapause}

Diapause intensity (preoviposition period) was consistently higher in the Czech samples than in the Bulgarian ones, and corresponded to the difference in cold hardiness. However, correlation of preoviposition period with SCP and $\mathrm{LT}_{50}$ was weak, and only slightly significant with $\mathrm{Lt}_{50}$. Although diapause terminated in January, SCP in January and November was the same, and survival decreased only slightly. Diapause is a prerequisite for cold acclimation (Hodková \& Hodek, 1994; in agreement with Denlinger, 1991) but during winter, cold hardiness is not dependent on diapause.

\section{Geographical differences}

Both monthly mean temperatures and monthly minima were on average $1^{\circ} \mathrm{C}$ higher at the Bulgarian than at the Czech locality over the period of the study. This is a smaller difference than that recorded during the growing season and during a typical year. Although Sofia is situated at a higher altitude than České Budějovice, this does not compensate for the difference in latitude. Absolute minima in winter may be $-15^{\circ} \mathrm{C}$ in Sofia, but well below $-20^{\circ} \mathrm{C}$ in České Budějovice.

The clear difference in mean SCP of the two populations of $P$. apterus ( 5 degrees in mid-winter) is a rare phenomenon. Such differences between populations were found in pupae of Delia radicum (Turnock et al., 1985,
1990,1998 ), (population means from -20 to $-25^{\circ} \mathrm{C}$ ) but were not correlated with the winter severity they experienced. In overwintering Aglais urticae, SCPs were similar $\left(-21^{\circ} \mathrm{C}\right)$ at two locations with very different winter temperatures (Lozina-Lozinskii, 1974; Pullin \& Bale, 1989). Two closely related psyllids, Craspedolepta nebulosa and C. subpunctata, which differ in spatial distribution (only the former is present in northern Norway, both in Britain), show similar supercooling and low temperature survival (Bird \& Hodkinson, 1999), and the two populations of C. nebulosa (British, $53^{\circ} \mathrm{N}$ vs. Norvegian, $69^{\circ} \mathrm{N}$ ) have similar SCPs $\left(-22.5\right.$ vs. $\left.-21.6^{\circ} \mathrm{C}\right)$.

The difference between populations of $P$. apterus is associated with the SCP being a good indicator of cold hardiness in this species (Hodková \& Hodek, 1997), whereas it is a weak predictor of survival in other species (the psyllids Craspedolepta; Bird \& Hodkinson, 1999; the fly Delia; Turnock et al., 1998). In the case of the two species of Craspedolepta, the difference in geographical distribution is not associated with their ability to survive cold winters, but with their thermal requirements for development. The importance of the differences in the cold hardiness of individuals from two populations of $P$. apterus from localities with different climates is enhanced by the fact that it was demonstrated repeatedly during the course of a winter.

The two populations differ also in other biological parameters. The Bulgarian bugs are smaller than the Czech bugs. Mean body lengths of 17 subpopulations of P. apterus from central Bohemia (Honěk, 1986) are similar to the mean of the individuals from southern Bohemia used in this study, or are slightly smaller (males 8.9-9.6 $\mathrm{mm}$, females $9.4-9.8 \mathrm{~mm}$ ), but much bigger than the mean length of the Bulgarian bugs.

\section{Environmental conditions}

The SCPs did not follow changes in ambient temperatures in the original localities of the respective populations. The mean air temperatures in the month of measurement and the monthly minimum together explained $33 \%$ of the variability in SCP, with both the partial and total correlation coefficients not significantly different from zero. The correlation between the SCP and ambient temperature in the month preceeding the measurement was even lower ( $5 \%$ explained variability). Minimum air temperatures in mid- and late winter were lower than the mean SCP at both localities (Fig. 1), but did not kill a high proportion of the bugs in their shelters. The temperatures in the overwintering microhabitat (leaf litter) of the bugs fluctuates much less than air temperature. Košt'ál \& Simek (2000) showed that the temperatures are stable $\left(+2.5\right.$ to $\left.-2.5^{\circ} \mathrm{C}\right)$ from December to February, despite fluctuations in air temperature $\left(+14\right.$ to $\left.-17^{\circ} \mathrm{C}\right)$.

The correlations between lethal time at $-7^{\circ} \mathrm{C}$ and the ambient temperature of the current or preceding months, were weak (3-4\% explained variability), whereas those with lethal temperature after 3 day exposure were higher (49-53\%), but not significant. Bugs become cold hardy by entering a diapause, and by low temperatures experienced earlier in the season. Similarly, Košt'ál \& Šimek 
(2000) found that cold hardiness (SCP, survival) generally followed changes in mean air temperature during the year, but were not closely related during winter [lower temperature in January was followed by a weaker cold hardiness (survival at $-15^{\circ} \mathrm{C}$ )]

\section{Acclimation}

Hodková \& Hodek (1994) reported that induction of diapause was a prerequisite for cold acclimation in $\mathrm{Pyr}$ rhocoris apterus: SCP decreased by $5^{\circ} \mathrm{C}$ during early diapause at a rearing temperature of $26^{\circ} \mathrm{C}$, and by another $5^{\circ} \mathrm{C}$ during subsequent cold acclimation in the thermoperiod of $20 / 5^{\circ} \mathrm{C}$. In a later study Hodková \& Hodek (1997) showed that a temperature of $15^{\circ} \mathrm{C}$ was more effective than $5^{\circ} \mathrm{C}$ in cold hardening. Despite the great decrease in temperatures from November to January, the Czech population did not increase in cold hardiness above the level achieved in autumn.

The SCPs of the Bulgarian bugs did not decrease outdoors in Bohemia (Table 4), where the Czech population achieved a $5^{\circ} \mathrm{C}$ lower SCP. We suggest that differences in cold hardiness of these two populations are genetically determined, and reflect the evolutionary history of each population and the long-term climatic conditions at each locality, rather than the experimental conditions.

After diapause termination, a low SCP is maintained by low ambient temperatures, but increases irreversibly after a week at $26^{\circ} \mathrm{C}$, irrespective of photoperiod (Hodková \& Hodek, 1994). In the November sample the SCPs increased in the laboratory $\left(25^{\circ} \mathrm{C}\right)$ at both photoperiods, but only after 4 weeks. That is, before termination of diapause, a short exposure to high temperatures, which may occur even in natural habitats, did not affect cold hardiness in P. apterus. In the January sample, the SCP increased after a week of high temperature acclimation, and was slightly higher under long-day conditions ( -6 vs. $-7^{\circ} \mathrm{C}$ under short-day conditions). These correspond to the values found for the Czech population (this study and Hodková \& Hodek, 1994), while the SCPs were even higher outdoors in Bulgaria $\left(-5^{\circ} \mathrm{C}\right)$, maybe due to advanced gonad development.

ACKNOWLEDGEMENTS. This study forms part of a cooperative programme between the Institute of Zoology, Bulgarian Academy of Sciences and the Institute of Entomology, Academy of Sciences of the Czech Republic. The study was supported by grant No. 206/97/0619 of the Grant Agency of the Czech Republic, grant KONTAKT ME 169, and a grant from the Bulgarian National Research Fund.

\section{REFERENCES}

BALE J.S. 1993: Classes of insect cold hardiness. Funct. Ecol. 7: $751-753$

BALE J.S. 1996: Insect cold hardiness: A matter of life and death. Eur. J. Entomol. 93: 369-382.

Bird J.M. \& HodKInSON I.D. 1999: Species at the edge of their range: The significance of the thermal environment for the distribution of congeneric Craspedolepta species (Sternorrhyncha: Psylloidea) living on Chamerion angustifolium (Onagraceae). Eur. J. Entomol. 96: 103-109.
Casagrande R.A. \& Haynes D.L. 1976: A predictive model for cereal leaf beetle mortality from subfreezing temperatures. Envir. Entomol. 5: 761-769.

Denlinger D.L. 1991: Relationship between cold hardiness and diapause. In Lee R.E. Jr. \& Denlinger D.L.: Insects at Low Temperature. Chapman \& Hall, New York, pp. 175-198.

HANČ Z. 1998: Survival of Insects at Low Temperatures, Nonfreeze Mortality and Effect of Low Temperature Exposures Intermuted by Higher Temperatures. MSc thesis, Univ. South Bohemia, Čské Budějovice, 35 pp. (in Czech).

HANČ Z. \& NEDVĚD O. 1999: Chill injury at alternating temperatures in Orchesella cincta (Collembola: Entomobryidae) and Pyrrhocoris apterus (Heteroptera: Pyrrhocoridae). Eur. J. Entomol. 96: 165-168.

HoNĚK A. 1986: Body size and fecundity in natural populations of Pyrrhocoris apterus L. (Heteroptera, Pyrrhocoridae). Zool. Jb. Syst. 113: 125-140.

Hodková M. \& Hodek I. 1994: Control of diapause and supercooling by the retrocerebral complex in Pyrrhocoris apterus. Entomol. Exp. Appl. 70: 237-245.

HodKovÁ M. \& HodEK I. 1997: Temperature regulation of supercooling and gut nucleation in relation to diapause of Pyrrhocoris apterus (L.) (Heteroptera). Cryobiology 34: 70-79.

KošŤÁl V. \& ŠrMeK P. 2000: Overwintering strategy in Pyrrhocoris apterus (Heteroptera): the relations between life-cycle, chill tolerance and physiological adjustments. J. Insect Physiol. (in press).

Lee R.E. JR., Dommel A., Joplin K.H. \& Denlinger D.L. 1995: Cryobiology of the freeze-tolerant gall fly Eurosta solidaginis: Overwintering energetics and heat shock proteins. Climate Res. 5: 61-67.

LozINA-LozINskir L.K. 1974: Studies in Cryobiology. Wiley, New York, 260 pp.

NEDVẼD O. 1998: Modeling the relationship between cold injury and accumulated degree days in terrestrial arthropods. CryoLetters 19: 267-274.

Nedvẽd O., Hodková M., Brunnhofer V. \& Hodek I. 1995: Simultaneous measurement of low temperature survival and supercooling in a sample of insects. CryoLetters 16: 108-113.

NedVĚd O., LAVY D. \& Verhoef H.A. 1998: Modeling timetemperature relationship in cold injury and effect of high temperature interruptions on survival in chill sensitive collembolan. Funct. Ecol. 12: 816-824.

Pullin A.S. \& Bale J.S. 1989: Effects of low temperature on diapausing Aglais urticae and Inachis io (Lepidoptera: Nymphalidae): cold hardiness and overwintering survival. $J$. Insect Physiol. 35: 277-281.

StatSoft, Inc. 1997: Electronic Statistics Textbook. Tulsa, OK, StatSoft, http://www.ststsoft.com/textbook/stathome.html.

TurNock W.J., Borvin G. \& Ring R.A. 1998: Interpopulation differences in the cold-hardiness of Delia radicum (Diptera: Anthomyidae). Can. Entomol. 130: 119-129.

Turnock W.J., Jones T.H. \& ReAder P.M. 1985: Effects of cold stress during diapause on the survival and development of Delia radicum (Diptera: Anthomyidae) in England. Oecologia 67: $506-510$.

Turnock W.J., Reader P.M. \& Bracken G.K. 1990: A comparison of the cold hardiness of populations of Delia radicum (L.) (Diptera: Anthomyidae) from southern England and the Canadian Prairies. Can. J. Zool. 68: 830-835.

Received November 11, 1999; accepted February 22, 2000 